\title{
Development of E-learning systems in technical universities
}

\author{
Gavril Musca*, Andrei Marius Mihalache and Lucian Tabacaru \\ Gheorghe Asachi Technical University of Iasi, Department of Machine Manufacturing Technology, \\ Blvd. D. Mangeron, No.59A, Iasi-700050, Romania
}

\begin{abstract}
Electronic learning, distant learning, collaborative work, mobile learning and internet based learning concepts are ever more present in superior learning systems. At this date for study or for finding different information we may access different search engines (like Google) where we can consult information based websites, blogs or online tutorials. Elearning systems can be grouped in online systems that have no direct interaction between the students and the professor, face to face systems that use both electronic resources and student-professor interaction, selflearning systems based on blogs, tutorials, teaching programs or web based systems. We can safely assume that e-learning is rapidly growing and that many universities have online free platforms developed for aiding students. The technological leap of current industries poses new challenges for the traditional educational systems. Efforts are known and acknowledged for changing and enhancing the existent educational systems and the orientation towards online learning processes.
\end{abstract}

\section{Introduction}

Universities are expanding constantly their educational offers by giving students rapid access to quality and up to date information in form of an efficient organized content. Teaching mechanical students as well as training specialists from the industrial environment requires sustained efforts from teachers, trainers and students. Actual performances of CAD, CAM, CAE, PDM and PLM solutions impose a continuous adaptation to performance and engineering processes quality requirements. This is why elearning represents a modern solution which answers up to date demands.

\section{Implementation of E-learning in universities}

Because of the growing popularity of e-learning systems many universities offer online learning platforms which are based on distant learning [1], [3], [4], [13], [16], and [17]. A major concern is represented by the transition to an online learning system with sustainable ever increasing quality of students-professor relationships.

\footnotetext{
*Corresponding author: musca@tcm.tuiasi.ro
} 
At Helsinki University there have been analyzed various e-learning platforms from the perspective of cost and productivity [3]. This university offers e-learning courses of technology, business, culture and social services. It is being considered that e-learning platforms do not always mean distant learning thus being applicable to face to face learning systems as well. The e-learning systems have revolutionized learning processes with up and downs. From downs we may record web systems which have incomplete or false information which may lead to inappropriate learning methods or even wrong knowledge. But we cannot oversee the undeniable advantages of computer based learning processes like ease of search and finding data, the possibility to keep information for future use, gaining success in short periods of time and gaining good solid results [2], [10].

The architecture of an e-learning system is difficult to understand in technical form ([3], [5], [6]) but in short is being made out of: user interface which represents what the student sees when accessing the e-learning system, the working platform represents the media that the learning system is built on and the database which contains all data and resources of the learning system, students related information and the very structure of the study process. The interface consists of the influence between the web platforms upon the learning system's database. The platform itself can be free (open source) or commercial developed inside an expensive programming software solution. Out of free e-learning systems we would like to mention: Efront learning, Moodle, Ilias, Dokeos, Sakai, Claronline, Atutor, OLAT, Colloquia ([3], [15], and [18]) and from the most known commercial systems: Blackboard, Angel, WebCT, Desire2Learn, SumTotalSystem or KnowkedgePlanet. The term of E-learning is derived from electronic learning and has been defined by many researchers. Thus, e-learning is defined by all activities relevant to training, teaching and learning by various electronic means such as internet, TV, video/audio or other supported media. Other researchers agreed on a much simpler definition: a teaching process sustained by using information technology and modern computers.

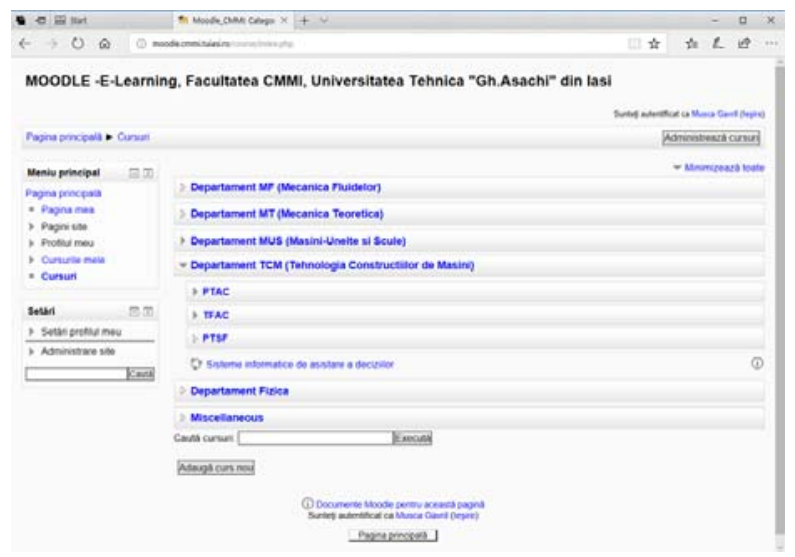

Fig. 1. General view of an e-learning system and the course studies that it contains.

With all the advantages of such a learning system the results can be unsatisfactory due to their main beneficiaries, namely students. The best way to obtain better results is by enhancing interactions between teachers-teachers, students-students and teachers-students. In a way of speaking, the e-learning system creates more problems than it resolves. If the system has user difficulty problems than student attitude may become hostile. By analyzing several systems we have formulated few conclusions:

- Decision factors from the universities must pay attention to students from humanistic departments in order to enhance their skills in computer based searches and internet 
browsing as part of their classes as well as raising the awareness degree about the benefits of managed learning systems,

- Students qualified to use an e-learning system (moodle) are aware and recognize its main advantages,

- Results have shown that the utility and ease of use are factors that affect directly the degree of acceptance from students of such systems,

- Positive attitude of students regarding e-learning systems has been given by the ease of use and not at the invitation of decision factors from the universities.

In some institutions electronic learning has already fully replaced traditional teaching methods as in others they are complemented by classic courses. Another study reveals the situation present in Ljubljana University which offers public administration programs [18]. Preoccupations for using electronic education exist in many countries. Paper [13] presents the stages of Bulgarian distant learning applied at Stara Zagora University. The development and implementation of such an e-learning system has required training of staff in order to create courses as well as application of databases management methods in Moodle. Moodle implementation has been monitored first for informatics, programming and information technology type of classes. It is mandatory to evaluate and grade each student related activity. In order to do this, each activity has to be materialized in form of a report but also in a language used in learning [11].

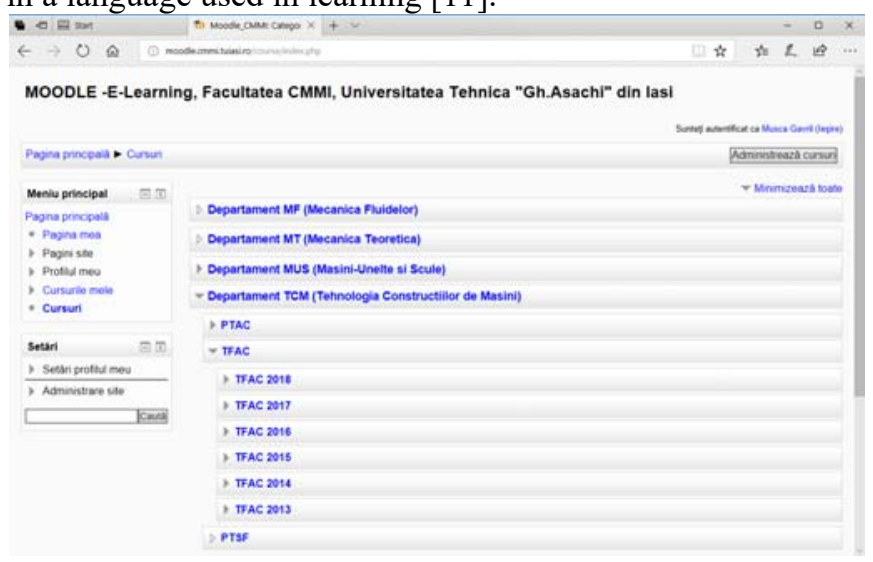

Fig. 2. Moodle based courses structure.

It is been considered that using an e-learning system is useful for distant learning educational systems. Engaging teachers alongside students in such activities raises the overall quality and ensures the collaboration between parts. Teachers and students have different perceptions about the utility of e-learning systems. Paper [7] presents a study used to evaluate electronic teaching systems in Kenya. The study had two objectives: e-learning platform status evaluation and the evaluation of the degree of use in the implementation of electronic educational systems in Kenyan universities. The conclusion was that due to the lack of computers inside laboratories and other logistics the acceptance degree is very low and the classic courses are forward very popular among teachers and decision factors.

Problems that appear in the implementation process of an e-learning platform inside economical educational systems are presented in paper [9]. One of the many problems that has been acknowledged is that of teachers and students are rarely using the debate system available through forums still preferring face to face interactions. There are several factors which influence the efficiency degree of an e-learning platform. It is also very important to understand them and to find proper available tools for a positive teaching and learning experience to be produced. For example, many students have different learning styles and the development of a Moodle based course of study may reduce the overall quality of the 
educational process. Hungarian studies showed that Moodle proved to be an excellent tool due to its extended capabilities of developing rich learning materials and saving them in very logical manner but also for being an online collaborative platform for students and teachers as well as researchers [6]. Those features marked a better educational system which proved to be more efficient and intuitive.

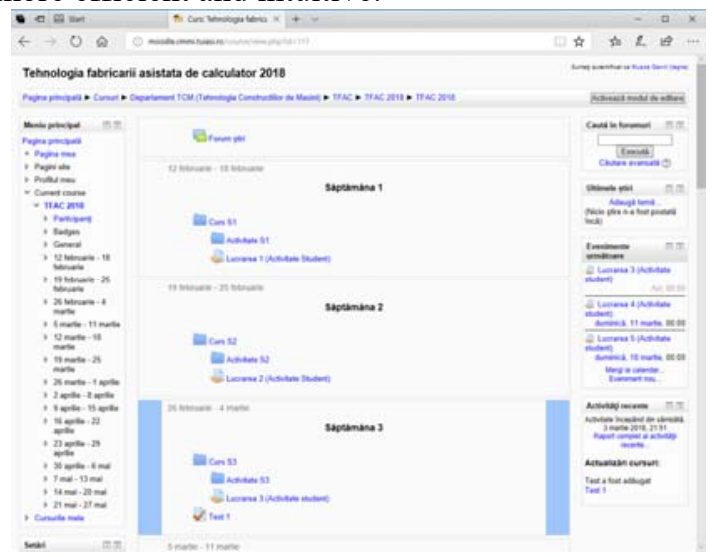

Fig. 3. Definition for semester courses.

The implementation of e-learning systems are known among Romanian universities such as ([17], [19] and [20]): Polytechnic University of Bucharest, Polytechnic University of Timisoara, Babes-Bolyai and the Technical Universities of Cluj-Napoca, Ovidius University of Constanta, Pitesti University, Sibiu University and Suceava University. Timisoara University has participated in a project that develops an e-learning system along universities from Romania, Finland, Italy, Great Britain, Lithuania and Hungary (ViCaDiS), [19]. Departments from the Technical University of Iasi have their own elearning systems. Some are developed for resources highlighting teaching material presentations. One of the main issues that occur in the development process of an e-learning system is that of quality evaluation and optimization of its components [8], [12]. As results we believe that the development of a learning system is a dynamic activity unrolled on several years which contains both the resources elaboration procedure and the student activity assessments. Implementation of Moodle management systems knows multiple domains of use but also connecting means such as computer networks, cloud solutions, mobile phones and tablets [4], [7]. The applications for e-learning systems is complex and varies from education to the most dynamic economic ones where rapid training and personnel adaptation is required in short period of times [5], [6], [14].

\section{Courses development in Computer Aided Manufacturing on Moodle e-learning system}

The requirements of learning in the engineering field have imposed the development of an e-learning system inside the CAD/CAM laboratory of the Machine Manufacturing Technology Department of the Technical University of Iasi, Romania. The first version was functional in 2013 using a local server. At this moment the system is extended and works on the University's server in such a way that all departments have access (see Figure 1). The platform contains 12 courses and has been used by over 780 students from bachelor and master degrees (see Figure 2). Resources available to students are made of author's original manuals, tutorials and software documentations used in design and manufacturing (Solid Edge, NX CAM, ESPRIT, and CIMCO), scientific articles and web links to relate to 
field websites. At start students are enrolled and gain access credentials (user and password). In order to avoid the errors of misunderstandings or poor knowledge an individual type of enrollment was used as well as enrollment of working groups both done by teachers. For a better students-teacher interaction one option for a picture assigned profile was chosen for social media, debates, messages, assessments, results and different announcements.

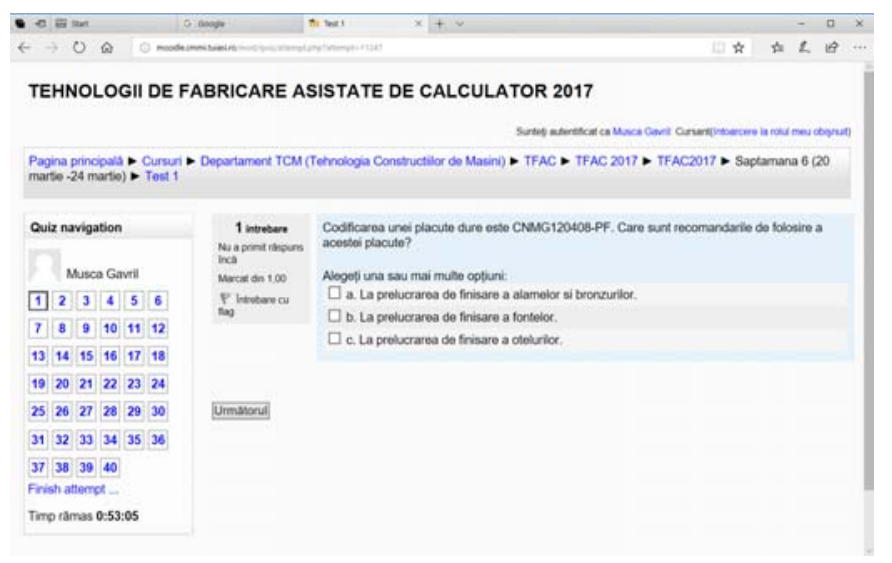

Fig. 4. The interface of a knowledge verification test.

Each course has a curriculum corresponding structure and lasts for 14 weeks (see Figure 3 ). For each week working resources are programmed (course, links, additional biography) as well as student activities (presence, applications, tests and forum debates participation). The test are compiled on course chapters. The students undertake three or four types of tests with multiple answer possibilities or essays (see Figure 4). Upon completion the students receive two homework about design of the manufacturing technologies for CNC mills and lathes and one that encapsulates all significant course elements.

\section{Conclusions}

Analyzing different studies showed that the management of learning systems knows various applications and approaches. Using cloud solutions, dedicated networks, smartphones or tablets represents the future for e-learning systems. Boosting performances of the above mentioned systems will increase further more the awareness for the e-learning solutions making them more attractive as they will succeed in compiling up to date information. The quality of information contained inside e-learning courses is crucial for a successful implementation. Updating information through student activities structuring in terms of thoroughgoing study to proposals of applications designed to be easily understood and put to practice is a full time requirement for any teacher who plans to take his activity to the next level. The appearance of new data in engineering has led to the idea of a continuous improvement of the materials disseminated. This is why new courses appear every year. The authors appreciate that a successful Moodle based developed course of study is still based on the interaction between students and teacher and students. In the case of Computer Aided Design or Manufacturing courses there are necessary applications which must ensure a proper knowledge and understanding of CNC centers, tools and holders, material specifications and related working regimes, NC programming languages as well as CAM software used in the simulation of manufacturing or for generation of the numerical codes. The success of an e-learning systems ultimately depends on the quality of the materials, student's results and their degree of confidence. 


\section{References}

1. T. Almarabeh, H. Mohammad, R. Yousef, and Y. K Majdalawi. Journal of Software Engineering and Applications 7, 999-1007 (2014)

2. G. Belgiu, C. Cărausu, and F. Grosu. International Journal of Modern Manufacturing Technologies 9(1), 6-13 (2017)

3. N. Guragain. E-Learning Benefits and Applications, thesis Bachelor of Engineering, pp. 53 (Helsinki Metropolia University of Applied Sciences, Information Technology, 2016)

4. C. Drago, Optimization of a M-learning and E-learning Methods in Metrology Education, Faculty of Electrical Engineering and Computing, Zagreb, Croatia, Faculty of Engineering, Benevento, Italy

5. L.A. Dobrzański, F. Brom. Journal of Achievements in Materials and Manufacturing Engineering 29(1), (2008)

6. P. Lengyel, M. Herdon. E-Learning Course Development in Moodle, Proceeding of the International Conference BIOATLAS 2008 Transilvania University of Brasov, Romania (2008)

7. N.K. Kiget, G. Wanyembi, A.I. Peters. International Journal of Advanced Computer Science and Applications 5(8), 07-102 (2014)

8. E. Kurilovas, V. Dagiene. Electronic Journal of e-Learning 8(2), 141-150 (2010)

9. M. Daniel, E-learning @ Divine Word University: Use of Moodle, Contemporary PNG Studies. DWU Research Journal 11, 63-78 (2009)

10. V. Merticaru, M.I. Ripanu, G. Nagit, Annals of the Oradea university, Fascicle of Management and Technological Engineering, XIX (IX), 140-149 (2010)

11. G. Musca, E. Musca, V. Merticaru, Academic Journal of Manufacturing Engineering 9(4), 72-77 (2011)

12. G. Nagit, A.M. Mihalache. Applied Mechanics and Materials 371, 463-467 (2013)

13. V. Nedeva. Journal of Sciences 3(7), 12-19 (2005)

14. M.I. Ripanu, G. Nagit, V. Merticaru, A.M. Mihalache, M. Boca, V. Husanu. Applied Mechanics and Materials 657, 183-187 (2014)

15. W. Torbacki, Journal of Achievements in Materials and Manufacturing Engineering 22(1) (2007)

16. C. Silvestru, I. Burcezan (Precup), R. Bere, M. Lupescu. Informatica Economica 19(2), 90-99 (2015)

17. B. Tiganoaia. Convergent discourses. Exploring the Contexts of Communication Arhipelag ( XXI Press, 2016)

18. L. Umek, A. Aristovnik, N. Tomaževič \& D. Keržič. Eurasia Journal of Mathematics, Science \& Technology Education 11(6), 1495-1505 (2015)

19. *** Project Concord, POSDRU/87/1 .3/5/61397, National net for continuous training of the didactic staff from the pre-university professional and technical education (in Romanian) (Universitatea Politehnica din București, 2011)

20. *** Proiect ERASMUS, EU Life Long Learning Programme - Virtual Campus 'Virtual Campus for Digital Students - ViCaDiS' 134039-LLP-1-2007-RO-ERASMUS-EVC (2007) 